Viviane Tyssandier, Emmanuelle Reboul, Jean-François Dumas, Corinne

Bouteloup-Demange, Martine Armand, Julie Marcand, Marcel Sallas and Patrick

Borel

Am J Physiol Gastrointest Liver Physiol 284:913-923, 2003. First published Jan 10, 2003;

doi:10.1152/ajpgi.00410.2002

You might find this additional information useful...

This article cites 47 articles, 20 of which you can access free at:

http://ajpgi.physiology.org/cgi/content/full/284/6/G913\#BIBL

This article has been cited by 8 other HighWire hosted articles, the first 5 are:

Digestive Stability of Xanthophylls Exceeds That of Carotenes As Studied in a Dynamic in

Vitro Gastrointestinal System

S. Blanquet-Diot, M. Soufi, M. Rambeau, E. Rock and M. Alric

J. Nutr., May 1, 2009; 139 (5): 876-883.

[Abstract] [Full Text] [PDF]

Lycopene Absorption in Human Intestinal Cells and in Mice Involves Scavenger Receptor Class B Type I but Not Niemann-Pick C1-Like 1

M. Moussa, J.-F. Landrier, E. Reboul, O. Ghiringhelli, C. Comera, X. Collet, K. Frohlich, V.

Bohm and P. Borel

J. Nutr., August 1, 2008; 138 (8): 1432-1436.

[Abstract] [Full Text] [PDF]

In Vitro Micellarization and Intestinal Cell Uptake of cis Isomers of Lycopene Exceed

Those of All-trans Lycopene

M. L. Failla, C. Chitchumroonchokchai and B. K. Ishida

J. Nutr., March 1, 2008; 138 (3): 482-486.

[Abstract] [Full Text] [PDF]

\{beta\}-Carotene Micellarization during in Vitro Digestion and Uptake by Caco-2 Cells Is Directly Proportional to \{beta\}-Carotene Content in Different Genotypes of Cassava

S. K. Thakkar, B. Maziya-Dixon, A. G. O. Dixon and M. L. Failla

J. Nutr., October 1, 2007; 137 (10): 2229-2233.

[Abstract] [Full Text] [PDF]

Bioavailability of Carotenoids and Tocopherols from Broccoli: In Vivo and In Vitro

Assessment

F. Granado, B. Olmedilla, C. Herrero, B. Perez-Sacristan, I. Blanco and S. Blazquez

Exp Biol Med, December 1, 2006; 231 (11): 1733-1738.

[Abstract] [Full Text] [PDF]

Updated information and services including high-resolution figures, can be found at:

http://ajpgi.physiology.org/cgi/content/full/284/6/G913

Additional material and information about AJP - Gastrointestinal and Liver Physiology can be found at:

http://www.the-aps.org/publications/ajpgi

This information is current as of September 6, 2010 .

AJP - Gastrointestinal and Liver Physiology publishes original articles pertaining to all aspects of research involving normal or abnormal function of the gastrointestinal tract, hepatobiliary system, and pancreas. It is published 12 times a year (monthly) by the American Physiological Society, 9650 Rockville Pike, Bethesda MD 20814-3991. Copyright @ 2003 by the American Physiological Society. ISSN: 0193-1857, ESSN: 1522-1547. Visit our website at http://www.the-aps.org/. 


\title{
Processing of vegetable-borne carotenoids in the human stomach and duodenum
}

\author{
Viviane Tyssandier, ${ }^{1}$ Emmanuelle Reboul, ${ }^{2}$ Jean-François Dumas, ${ }^{1}$ \\ Corinne Bouteloup-Demange, ${ }^{3}$ Martine Armand, ${ }^{2}$ Julie Marcand, ${ }^{1}$ \\ Marcel Sallas, ${ }^{1}$ and Patrick Borel ${ }^{2}$ \\ ${ }^{1}$ Unité Maladies Métaboliques et Micronutriments, Institut National de la Recherche Agronomique, \\ Clermont-Ferrand/Theix, 63122 Saint-Genès-Champanelle; ${ }^{3}$ Unité d'Exploration en Nutrition, Laboratoire \\ de Nutrition Humaine du Centre de Recherche en Nutrition Humaine d'Auvergne, 63000 Clermont-Ferrand; \\ and ${ }^{2}$ Unité INSERM 476, Faculté de Médecine, 13385 Marseille Cedex 05, France
}

Submitted 24 September 2002; accepted in final form 27 December 2002

Tyssandier, Viviane, Emmanuelle Reboul, JeanFrançois Dumas, Corinne Bouteloup-Demange, Martine Armand, Julie Marcand, Marcel Sallas, and Patrick Borel. Processing of vegetable-borne carotenoids in the human stomach and duodenum. Am J Physiol Gastrointest Liver Physiol 284: G913-G923, 2003. First published January 10, 2003; 10.1152/ajpgi.00410.2002.—Carotenoids are thought to diminish the incidence of certain degenerative diseases, but the mechanisms involved in their intestinal absorption are poorly understood. Our aim was to obtain basic data on the fate of carotenoids in the human stomach and duodenum. Ten healthy men were intragastrically fed three liquid test meals differing only in the vegetable added $3 \mathrm{wk}$ apart and in a random order. They contained $40 \mathrm{~g}$ sunflower oil and mashed vegetables as the sole source of carotenoids. Tomato purée provided $10 \mathrm{mg}$ lycopene as the main carotenoid, chopped spinach (10 mg lutein), and carrot purée (10 mg $\beta$-carotene). Samples of stomach and duodenal contents and blood samples were collected at regular time intervals after meal intake. all-trans and cis carotenoids were assayed in stomach and duodenal contents, in the fat and aqueous phases of those contents, and in chylomicrons. The cis-trans $\beta$-carotene and lycopene ratios did not significantly vary in the stomach during digestion. Carotenoids were recovered in the fat phase present in the stomach during digestion. The proportion of all-trans carotenoids found in the micellar phase of the duodenum was as follows $($ means $\pm \mathrm{SE})$ : lutein $(5.6 \pm 0.4 \%), \beta$-carotene $(4.7 \pm 0.3 \%)$, lycopene $(2.0 \pm 0.2 \%)$. The proportion of 13 -cis $\beta$-carotene in the micellar phase was significantly higher $(14.8 \pm 1.6 \%)$ than that of the all-trans isomer $(4.7 \pm 0.3 \%)$. There was no significant variation in chylomicron lycopene after the tomato meal, whereas there was significant increase in chylomicron $\beta$-carotene and lutein after the carrot and the spinach meals, respectively. There is no significant cis-trans isomerization of $\beta$-carotene and lycopene in the human stomach. The stomach initiates the transfer of carotenoids from the vegetable matrix to the fat phase of the meal. Lycopene is less efficiently transferred to micelles than $\beta$-carotene and lutein. The very small transfer of carotenoids from their vegetable matrices to micelles explains the poor bioavailability of these phytomicroconstituents.

Address for reprint requests and other correspondence: P. Borel, INSERM U476, Faculté de Médecine, 27, Boulevard Jean Moulin, 13385 Marseille Cedex 5, France (E-mail: Patrick.Borel @medecine.univ-mrs.fr). $\beta$-carotene; lycopene; lutein; postprandial; absorption; bioavailability

EPIDEMIOLOGICAL STUDIES CONSISTENTLY associate diets rich in fruits and vegetables with a lower incidence of several diseases (22). The plant pigments, carotenoids, are assumed to be involved in this effect because of their antioxidant properties (20, 21).

In common foods, carotenoids are mostly found as all-trans isomers (25), but significant amounts of geometrical cis isomers can be produced during processing $(36,37)$. The cis isomers of $\beta$-carotene and lycopene have attracted attention, because several studies have suggested that their bioavailabilities are different from those of their corresponding trans isomers $(2,15,18$, 39 ) and that they may possess specific functions (16, $23,26,28$ ).

The absorption efficiency of all-trans $\beta$-carotene, the most extensively studied carotenoid, is generally poor but widely variable $(4,11)$, ranging between 3.5 and $90 \%$, depending on the dose, the matrix in which it is incorporated, and the method used to estimate absorption $(8,12,31,47)$. Data on the absorption efficiency of other carotenoids are scant, although such information is needed for dietary recommendations, supplement formulation, and the design of intervention studies involving carotenoids (33). Although a number of factors is thought to affect the bioavailability of carotenoids (46), much work remains to be done to identify the main factors among all those proposed. The mechanisms that might explain the low and variable absorption of carotenoids are largely unknown, because the fate of these micronutrients in the human upper gastrointestinal (GI) tract is still obscure. Three assumptions are currently made about carotenoid metabolism in the lumen of the human upper GI tract. First, carotenoids cannot be absorbed while they remain embedded in their original vegetable matrices. Second, carotenoids have to be solubilized in mixed micelles to

The costs of publication of this article were defrayed in part by the payment of page charges. The article must therefore be hereby marked "advertisement" in accordance with 18 U.S.C. Section 1734 solely to indicate this fact. 
be absorbed. Third, carotenoids are absorbed by passive diffusion [as suggested for $\beta$-carotene (17)]. These assumptions are not sufficient to understand the factors limiting the absorption of natural carotenoids. Further data are required on the role of the stomach in carotenoid absorption, possible cis-trans isomerization of carotenoids in the acidic environment of the stomach, the extent of release of carotenoids from their vegetable matrices, and the relative availabilities for absorption of cis and trans isomers of carotenoids.

The aim of this study was to ascertain the fate of the main natural human dietary carotenoids, i.e., $\beta$-carotene, lycopene, and lutein in their natural vegetable matrices, in the lumen of the human upper GI tract, and to determine whether this fate affects their bioavailability. For this purpose, we adapted a model, previously used by us to study lipids (1) and vitamins A and $\mathrm{E}$ (5) metabolism in the human GI tract, to study the metabolism of carotenoids supplied in their natural vegetable matrices.

\section{MATERIALS AND METHODS}

Subjects. Ten healthy male volunteers $(24.2 \pm 1.0 \mathrm{yr}$, $1.80 \pm 0.02 \mathrm{~m}$, and $74.7 \pm 3.5 \mathrm{~kg}$ ) were enrolled in the study after giving their written, informed consent. The study was approved by the Regional Ethical Committee on Human Experimentation of Auvergne (France). No volunteer had any history of GI disease or lipid metabolic disorders according to clinical examination, disease history, and fasting plasma lipid parameters [plasma total triacylglycerols $(0.53 \pm 0.03 \mathrm{mM})$ and plasma total cholesterol $(3.80 \pm 0.24$ $\mathrm{mM}$ ) concentrations were in the normal range]. No volunteer was taking any drugs known to affect GI function or lipid metabolism.

The subjects' usual diet was monitored by means of a 5-day food recall. This dietary recall was analyzed for nutrient composition using diet analysis software (GENI; Micro 6, Nancy, France) completed for carotenoids by a carotenoid food-composition database (6). The subjects consumed a typical Western diet, with $11.88 \pm 0.90 \mathrm{MJ} /$ day, $14.52 \pm 0.78 \%$ of energy as proteins, $33.82 \pm 1.90 \%$ as fat, $48.03 \pm 2.58 \%$ as carbohydrates, and $3.63 \pm 1.45 \%$ as alcohol. Carotenoid intake was as follows (mg/day): $\beta$-carotene $(3.8 \pm 0.8)$, lycopene $(2.1 \pm 0.5)$, lutein-zeaxanthin $(1.5 \pm 0.5), \alpha$-carotene $(0.9 \pm$ $0.3)$, and $\beta$-cryptoxanthin $(0.1 \pm 0.04)$.

Test meals. Each subject was given three test meals differing only in the vegetable added, 3 wk apart and in a random order. The test meal compositions are given in Table 1. Note that vegetables were the sole source of carotenoids. Tomato purée was used as the source of lycopene, carrot purée as the source of $\beta$-carotene, and chopped spinach as the source of lutein.

The amount of triacylglycerols incorporated in the meals $(40 \mathrm{~g})$ was designed to be in the range of usual human food intake. The meal components were always mixed in the same conditions: $30 \mathrm{~s}$ with an electric food blender (Vitamix, Seb, Paris, France) set at $1,500 \mathrm{rpm}$ for $15 \mathrm{~min}$ at $+4^{\circ} \mathrm{C}$ to homogenize the components and prepare a lipid emulsion. The amount of carotenoids provided by the meals $(\sim 10 \mathrm{mg}$ of the main carotenoid per meal) was slightly higher than that usually consumed by the subjects (see above) but was designed to accurately follow the fate of these micronutrients in the GI tract and in the chylomicron fraction. Note that the vegetables did not in compulsory contain only one type of
Table 1. Composition of test meals (g)

\begin{tabular}{lr}
\hline \hline Sunflower oil* & \\
Cow whey proteins $\dagger$ & 40.0 \\
Sucrose & 52.0 \\
Soy lecithins $\ddagger$ & 116.0 \\
Vegetables§ & 5.0 \\
$\quad$ Tomato purée (lycopene) & 33.6 \\
Carrot purée ( $\beta$-carotene) & 161.0 \\
Chopped spinach (lutein) & 99.0
\end{tabular}

*Unilever Health Institute, Unilever Research, Vlaardingen, Netherlands. †Lacprodan DI-9212, Arla Foods, Skanderborgvej, Denmark. $\ddagger$ Lécithine 100, Gerblé, Nutrition \& Santé, Revel, France. $\S$ These amounts of vegetable were chosen to provide similar amounts of carotenoids $\approx 10 \mathrm{mg}$ of the main carotenoid). Vegetable sources were provided by Institute of Food Research (Norwich, UK). $\mathrm{NaCl}(0.9 \%)$ was added to bring the volume to $600 \mathrm{ml}$. Carrots were peeled, diced, cooked, and pureed with the addition of $50 \%$ water to make the puree workable. Fresh spinach leaves were harvested and cooked on the same day. The harvest was split, and one-half was kept as whole leaf and the other half was chopped. The tomato meal provided $4.51 \mathrm{MJ}$ (37.2\% as fat, $43.4 \%$ as carbohydrates, and $19.4 \%$ as proteins). The carrot meal provided $4.65 \mathrm{MJ}$ (36.2\% as fat, $44.5 \%$ as carbohydrates, and $19.3 \%$ as proteins). The spinach meal provided 4.54 MJ (37.1\% as fat, $42.9 \%$ as carbohydrates, and $20.0 \%$ as proteins).

carotenoid. Indeed, carrot purée provided $10 \mathrm{mg} \beta$-carotene and $3.9 \mathrm{mg} \alpha$-carotene. Tomato purée provided $10 \mathrm{mg}$ lycopene and $1 \mathrm{mg} \beta$-carotene. Chopped spinach provided $10 \mathrm{mg}$ lutein, $7.1 \mathrm{mg} \beta$-carotene, and $0.3 \mathrm{mg}$ zeaxanthin.

Study design. Each procedure started at 07:30 AM after the subjects had fasted overnight for $12 \mathrm{~h}$. As previously described $(1,5)$, each subject was intubated with a singlelumen nasogastric tube (16 Fr, $122 \mathrm{~cm}$, Sherwood Medical Argyle, Tullamore, Ireland) and a single-lumen nasoduodenal tube (duodenographie bilboa-dotter set, $12 \mathrm{Fr}, 145 \mathrm{~cm}$, William Cook Europe, Bjaeverkov, Denmark). The stomach tube was located $45-50 \mathrm{~cm}$ from the nose in the stomach at the corpus-antrum junction. The duodenal tube was located at the junction of the second and the third portions of the duodenum. The position of the tubes was checked radiographically before meal intake. After the tubes were fitted, the volunteers adopted a sitting position that they maintained until the end of the study to limit variations in gastric emptying rates (19). An antecubital vein was catheterized with an intravenous cannula equipped with disposable obturators (Terumo Europe, Leuven, Belgium).

Fasting stomach juice and duodenal fluid were removed by manual aspiration just before ingestion of the liquid test meal. The $600-\mathrm{ml}$ liquid test meal was fed intragastrically by using a $60 \mathrm{ml}$-syringe over a 20 -min period. A 1-ml sample of the initial liquid test meal was kept for measuring emulsion droplet size. Large samples (100-200 ml) of the stomach contents were aspirated at $20,40,60,90,120,150$, and 180 min after meal intake by gentle aspiration with a $60-\mathrm{ml}$ syringe to obtain representative samples. A 20-ml aliquot was taken from each sample for analytical determinations. The remaining sample was promptly reinjected into the subject's stomach via the nasogastric tube. Duodenal contents $(5-10 \mathrm{ml})$ were aspirated at the same postprandial times as above by using the nasoduodenal tube. Portions $(2 \mathrm{ml})$ of the stomach content sample and portions $(0.5 \mathrm{ml})$ of the duodenal content sample were placed in glass tubes containing double volumes of chloroform/methanol [2:1 ( $\mathrm{vol} / \mathrm{vol})]$ to stop lipolysis and subsequently analyze lipids. Portions $(0.5 \mathrm{ml})$ of the sample were placed in tubes and stored at $4^{\circ} \mathrm{C}$ until the size of emulsion lipid droplets was determined (see Size of emul- 
sified lipid droplets). The remaining fractions of the samples were placed in another tube and stored at $-80^{\circ} \mathrm{C}$ until phase separation and carotenoid analysis (see Carotenoid analyses).

A baseline fasting blood sample $(0 \mathrm{~h})$ was collected. Blood samples $(14 \mathrm{ml})$ were drawn every hour for $8 \mathrm{~h}$ after test meal intake. Plasma was separated from whole blood by centrifuging $\left(910 \mathrm{~g}, 15 \mathrm{~min}, 4^{\circ} \mathrm{C}\right)$. Chylomicron plus large chylomicron remnants (Svenberg floatation unit $>1,000$ ) were isolated by ultracentrifuge as previously described (9).

Size of emulsified lipid droplets. The median size of emulsion lipid droplets was determined in the initial formulas and in the stomach and duodenal aspirates (just after collection) by using a particle size analyzer (Coulter LS 130, Coultronics, Margency, France). Mean sizes of emulsion lipid droplets were calculated by doing the mean of median size obtained after at least five measurements. In preliminary experiments, vegetable particles had been shown to affect the measurements, so they were discarded beforehand by centrifuging at $1,000 \mathrm{~g}$ for $2 \mathrm{~min}$ at $10^{\circ} \mathrm{C}$.

Separation of fat and aqueous phases from the vegetable particles present in the GI content samples. To assess the transfer of carotenoids from the vegetable matrices to the fat and aqueous phases present in the GI contents, we separated these two phases from the vegetable matrices. For the stomach content samples, the protocol was as follows: $7 \mathrm{ml}$ of stomach contents were placed in polyallomer tubes and centrifuged $\left(2,000 \mathrm{~g}, 10 \mathrm{~min}\right.$, at $4^{\circ} \mathrm{C}$ ). An aliquot (a few milligrams) of the floating oil phase, when present, was collected to measure carotenoid solubilized into the fat phase of the stomach. An aliquot of the infranatant was filtered through a sintered glass filter tube $(100 \mathrm{~mm}$ high, $20 \mathrm{~mm}$ in diameter, 40 - to $100-\mu \mathrm{m}$ pore size) (Prolabo, Fontenay-sous-Bois, France) to discard large $(>40 \mu \mathrm{m})$ particles of vegetable matrix. Liposomes and other aqueous soluble structures (phospholipid vesicles, proteins), which can potentially solubilize carotenoids in the aqueous phase of the stomach, were separated from small $(<40 \mu \mathrm{m})$ fat globules and small vegetable particles $(<40 \mu \mathrm{m})$ by ultracentrifuge $(200,000 \mathrm{~g}, 335$ $\min , 10^{\circ} \mathrm{C}$, in a Kontron TST 41.14 swinging bucket rotor) followed by filtration of the infranatant through a $0.2-\mu \mathrm{m}$ cellulose acetate filter (Schleicher \& Schuell, Prolabo, Fontenay-sous-Bois, France).

For the duodenal samples, the protocol was as follows: $4 \mathrm{ml}$ duodenal content were added with $7 \mathrm{ml}$ cold $\left(4^{\circ} \mathrm{C}\right)$ distilled water and placed in polyallomer tubes. The tubes were ultracentrifuged (same conditions as above) to float large lipid droplets and pellet vegetable particles. We noted that, in most of the duodenal samples, no floating oil layer was observed after the centrifugation. An aliquot of the infranatant was collected and filtered through a $0.2-\mu \mathrm{m}$ cellulose acetate filter to discard small fat globules and vegetable particles and measure carotenoids in micelles. Control optical microscopy showed there were no oil droplets or vegetable particles in the aqueous phase obtained after this filtration.

Lipid analysis. Lipids from stomach and duodenal samples were extracted in chloroform/methanol [2:1 (vol/vol)] (13). The lower chloroform phases were evaporated to dryness under nitrogen. Total lipids were determined gravimetrically. The extent of intragastric and intraduodenal triacylglycerol lipolysis was assessed at 40 min after meal intake in the stomach and at $1 \mathrm{~h}$ after meal intake in the duodenum. For that purpose triacylglycerols were separated from other lipid classes (diacylglycerols, monoacylglycerols, free fatty acids, free cholesterol, and esterified cholesterol) by twostage, one-dimensional thin-layer chromatography as described previously (1). They were quantified by densitometry by using a video-densitometry system and the Biolab software package (Visiosoft LND-CNRS patent, Marseille, France).

Chylomicron triacylglycerols were assayed by using an enzymatic colorimetric method with a commercial kit (Biotrol Diagnostic, Chennevières-lès-Louvres, France). The concentrations were measured spectrophotometrically at $490 \mathrm{~nm}$ by using an MR 700 microplate reader (Dsynatech Laboratories, Guernsey, UK).

Carotenoid analyses. A procedure to accurately extract carotenoids from the three different vegetable matrices and the stomach and duodenal samples was drawn up after preliminary experiments. Several combinations of solvents were tried, with the best combination being the one that gave the whitest vegetable matrix after extraction. The procedure, which was performed under yellow light, was as follows: 1-ml test meal or 2-ml stomach samples or 1-ml duodenal samples were added with $7 \mathrm{ml}$ methanol containing $0.57 \% \mathrm{MgCO}_{3}$ (Sigma, Saint Louis, MO) and $0.2 \mu \mathrm{g} / \mathrm{ml}$ internal standard (echinenone, Roche Vitamines France, Neuilly-sur-Seine, France). After homogenization for $30 \mathrm{~s}$ with a vortex blender, $7 \mathrm{ml}$ chloroform (containing $0.005 \%$ butylated hydroxytoluene as an antioxidant) were added. The sample was homogenized again for $30 \mathrm{~s}$ with the vortex blender. After $15 \mathrm{~min}$ rest, $7 \mathrm{ml}$ distilled water were added. After being centrifuged (2,000 g, $10 \mathrm{~min}$, room temperature), the lower phase containing most of the carotenoids was collected. Carotenoids remaining in the upper phase were extracted as follows: $5 \mathrm{ml}$ tetrahydrofuran was added, the mixture was then vortexed for $30 \mathrm{~s}$, and dichloromethane $(5 \mathrm{ml})$ was added. It was then vortexed for $30 \mathrm{~s}$, distilled water $(3 \mathrm{ml})$ was added, and it was vortexed again for $30 \mathrm{~s}$. After being centrifuged $(2,000 \mathrm{~g}, 10$ min, room temperature), the lower phase was collected and pooled with the previously collected phase. After evaporation to dryness under nitrogen, the dried extract was dissolved in either $200 \mu \mathrm{l}$ acetonitrile/dichloromethane [50:50 (vol/vol)] for the stomach and test meal samples or $200 \mu \mathrm{l}$ methanol/ dichloromethane [65:35 ( $\mathrm{vol} / \mathrm{vol})]$ for the duodenal samples. Chylomicron carotenoids were extracted by using a previously published method, i.e., twice with ethanol and hexane (29).

Carotenoids were quantified by reverse-phase HPLC on a Waters system (Waters, Saint-Quentin-en-Yvelines, France). This system was composed of a Waters 660 pump, a Waters 717 plus cooled auto-sampler, and a Waters 996 ultraviolet (UV)-visible diode-array detector. Carotenoids were separated by using two columns fitted in series (41): a $150 \times$ 4.6-nm RP $\mathrm{C}_{18}, 3-\mu \mathrm{m}$ Nucleosyl (Interchim, Montluçon, France) coupled with a $250 \times 4.6-\mathrm{nm} \mathrm{RP} \mathrm{C}_{18}, 5-\mu \mathrm{m}$ Vydac TP54 (Hesperia, CA). The mobile phase was an isocratic acetonitrile-dichloromethane-methanol (containing $50 \mathrm{mM}$ ammonium acetate)-water mixture (70:10:15:5, by vol). Carotenoids were detected at $450 \mathrm{~nm}$ and identified by retention time and spectral analysis (from 300 to $550 \mathrm{~nm}$ ) compared with pure $(>95 \%)$ standards of the following carotenoids: lutein, echinenone, all-trans lycopene, $\alpha$-carotene, all-trans $\beta$-carotene, and 13-cis $\beta$-carotene (Roche Vitamines). Because we had no pure standard of cis isomers of lycopene, the main cis isomers of lycopene (in terms of peak area), which were identified by their characteristic UV/Vis spectrum (with the small hypochromic shift in $\lambda_{\max }$ and the presence of a "cis peak" at $142 \mathrm{~nm}$ below the longest wavelength absorption maximum), were quantified by using the calibration curve of all-trans lycopene and called lycopene cis-isomers. Quantification was conducted by using Waters Millenium 32 software (version 3.05.01). The detection threshold was measured at $\sim 2 \mathrm{ng}$ carotenoid/HPLC injection. With the use of an internal standard, we calculated an overall recovery yield of 75- 
100\%. All the solvents used for carotenoid analyses were HPLC grade from Carlo Erba (Chaussée de Vexin, France).

\section{Calculations and Statistical Analysis}

The proportions of carotenoids remaining in the vegetable matrices in the stomach and duodenal contents were calculated by subtracting the carotenoids recovered in the lipid phase and in the aqueous phase from the total carotenoids measured in the samples. The extent of intragastric and intraduodenal triacylglycerol lipolysis was calculated as the percentage of triacylglycerols disappearing from the total acylglycerols present (triacylglycerols + diacylglycerols + monoacylglycerols). The area under the curves (AUCs) of the postprandial chylomicron responses (delta from fasting values) were calculated by the trapezoidal rule.

Subject characteritics and results are expressed as means $\pm \mathrm{SE}$. Data were tested for normality (KolmogorovSmirnov) before using parametric tests. Changes in measured parameters were analyzed by ANOVA. Two-factor ANOVA, with time and meal as factors, was used to study variations in stomach and duodenal $\mathrm{pH}$ during digestion. Variations in cis $\beta$-carotene and lycopene ratio during digestion were assessed by using two-factor ANOVA, with time and organ as factors. Proportions of carotenoids in micellar phase were compared by using two-factor ANOVA, with time and carotenoid type as factors. Variations in postprandial chylomicron carotenoid concentrations were assessed by ANOVA with repeated measures, with time as a factor. When significant $(P<0.05)$ differences were detected, means were compared between each other by using the post hoc Tukey/ Kramer's test. Pearson correlation coefficients were obtained from linear regression analyses. Statistics were performed using StatView software version 5.0 (SAS Institute, Cary, $\mathrm{NC})$.

\section{RESULTS}

\section{Stomach and Duodenum pH During Digestion}

Figure 1 shows variations in $\mathrm{pH}$ in stomach and duodenum contents after the intake of tomato, carrot, and spinach meals. As shown in Fig. $1 A$, the stomach $\mathrm{pH}$, which was $\sim 1.8$ in the fasting state, sharply increased to 5.4-6.2 after meal intake, then continuously decreased to reach 1.8-2.9 after 3 h digestion. A twofactor ANOVA showed there was no meal effect but a time effect on postprandial stomach $\mathrm{pH}$. The duodenal $\mathrm{pH}$ (Fig. $1 B$ ), which was $\sim 5$ in the fasting state, increased to $\sim 6.1-6.6$ after meal intake, and remained constant during digestion. Two-factor ANOVA showed a meal effect and no time effect on postprandial duodenal $\mathrm{pH}$. More precisely, the mean postprandial duodenal $\mathrm{pH}$ was significantly lower after the tomato meal $(5.8 \pm 0.1)$ than after the other two meals $(6.2 \pm 0.1$ and $6.4 \pm 0.1$ for the spinach and the carrot meal, respectively).

Size of Emulsion Lipid Droplets in Test Meals and in Stomach and Duodenal Contents During Digestion

In the test meals and in the stomach, lipid droplets exhibited monophasic distributions with bell-shaped curves (data not shown in the figures). In the duodenum, small droplets appeared (size 0.1-1 $\mu \mathrm{m}$ ) resulting in biphasic distributions. The mean diameter of
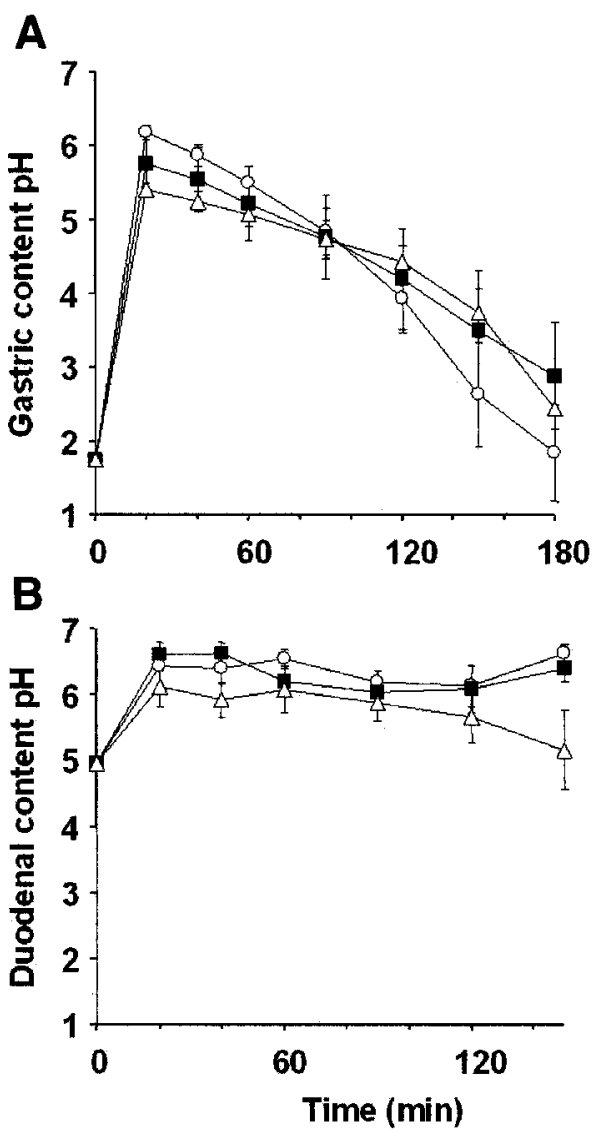

Fig. 1. Variations in $\mathrm{pH}$ in the upper gastrointestinal (GI) tract content during digestion. $A$ : stomach content. $B$ : duodenal content. $\bigcirc$, Carrot meal; $\mathbf{n}$, spinach meal; $\triangle$, tomato meal. Values represent means \pm SE of 10 separate measurements. Two-factor ANOVA, with time and meal as factors, showed no effect of meal on stomach $\mathrm{pH}$ but a significant $(P<0.001)$ effect of meal on duodenal $\mathrm{pH}$. It also showed a significant effect of time $(P<0.001)$ on stomach $\mathrm{pH}$ but not on duodenal $\mathrm{pH}$.

lipid droplets found in the carrot, tomato, and spinach meals was significantly different: $10.4 \pm 0.4,2.7 \pm 0.2$, and $8.1 \pm 0.8 \mu \mathrm{m}$, respectively. The mean diameter of lipid droplets found in the stomach after the carrot meal (mean of 3 measurements made at each collection time) was significantly higher than that measured after the tomato and the spinach meals: $15.1 \pm 0.7 \mathrm{vs}$. $6.1 \pm 0.9$ and $7.9 \pm 0.5 \mu \mathrm{m}$, respectively. The mean diameters of lipid droplets found in the duodenum after the carrot, the tomato, and the spinach test meals were $11.6 \pm 1.6,5.2 \pm 0.7$, and $4.8 \pm 0.6 \mu \mathrm{m}$, respectively.

\section{Triacylglycerol Lipolysis}

The relative amount of triacylglycerols present in the gastric aspirates at 40 min decreased by $12.6 \pm 1.8$, $14.3 \pm 2.5$, and $21.8 \pm 3.9 \%$ for the carrot, tomato, and spinach meal, respectively. In the 1 -h duodenal contents, triacylglycerol disappearance was more marked: $48.9 \pm 4.7,56.7 \pm 4.2$, and $47.0 \pm 9.2 \%$ for the carrot, tomato, and spinach meal, respectively. 

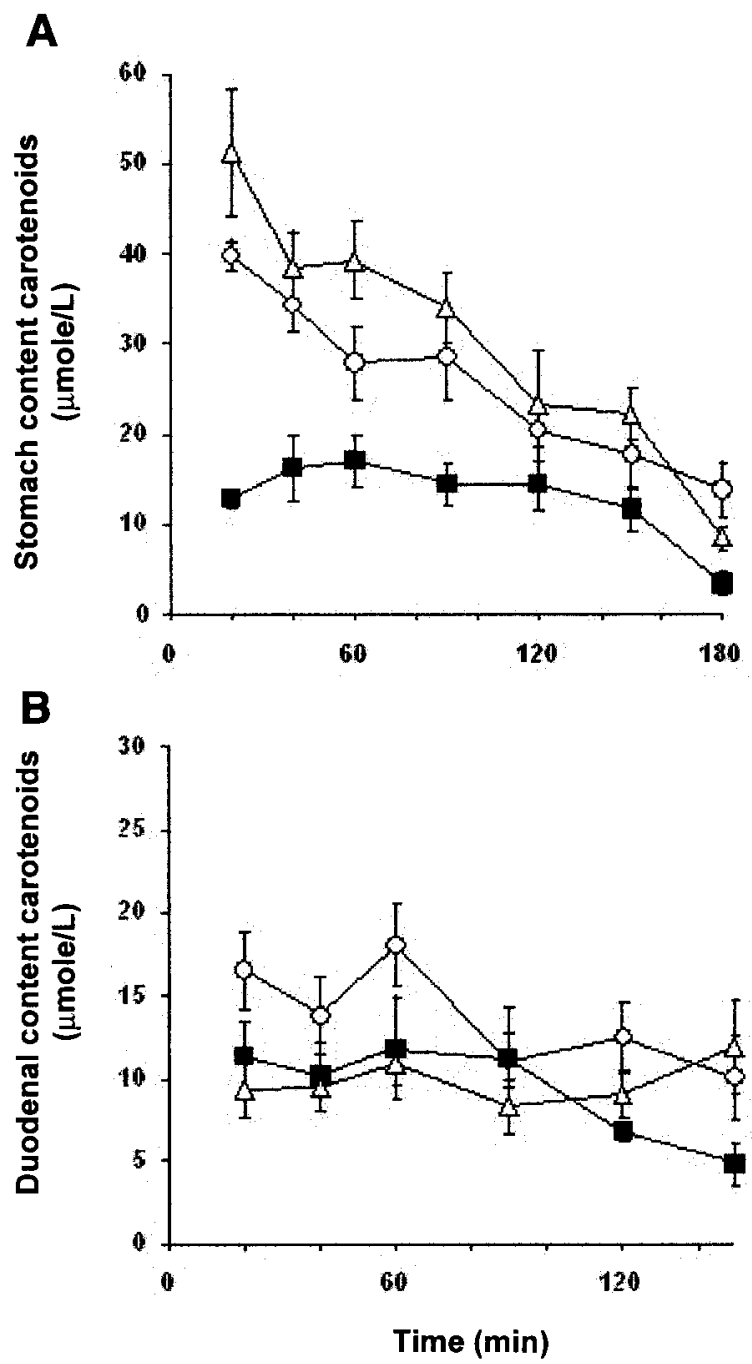

Fig. 2. Stomach and duodenal carotenoid concentrations during digestion. $A$ : stomach content. $B$ : duodenal content. $\square$, Lutein (after the spinach meal); $\bigcirc, \beta$-carotene (after the carrot meal); $\triangle$, lycopene (after the tomato meal). Values are means $\pm \mathrm{SE}$.

\section{Cartenoids in Fasting Stomach and Duodenal Contents}

After fasting, no carotenoids were detectable in the samples of stomach contents. Thus assuming a limited detection threshold of $2 \mathrm{ng}$ carotenoid per sample and given that the measurements were made on 2-ml stomach samples, we can assert that the concentration of carotenoids in the fasting stomach was lower than 2 nM. Conversely, carotenoids were detected in the fasting duodenum samples. Specifically, there were detectable amounts of lutein and all-trans $\beta$-carotene (155 \pm 51 and $30 \pm 9 \mathrm{nM}$, respectively) and no detectable amounts, i.e., $<4 \mathrm{nM}$ (the measurements were carried out with $1 \mathrm{ml}$ duodenum content), of $\alpha$-carotene, lycopene cis isomers, and $\beta$-carotene cis isomers.

\section{Concentration of Carotenoids in Stomach and} Duodenum During Digestion

Figure 2 shows that the concentration of carotenoids in the stomach gradually decreased during digestion.
Conversely, it ranged between 5 and $18 \mu \mathrm{M}$ in the duodenum and did not significantly vary during digestion. Stomach lutein concentration was significantly lower than $\beta$-carotene and lycopene stomach concentrations. Conversely, in the duodenum, there was no significant difference in the concentration of each carotenoid.

Proportion of cis Isomers of $\beta$-Carotene and Lycopene in Stomach and Duodenum During Digestion

Although the proportion of cis carotenoids in the stomach and in the duodenum did not vary significantly during digestion, it was significantly higher in the duodenum than in the stomach (Fig. 3). Specifically, the mean postprandial proportions of 13-cis $\beta$-carotene were $12.2 \pm 0.6$ and $8.0 \pm 1.5 \%$ in the duodenum and the stomach, respectively, and the mean postprandial proportions of cis lycopene were $13.6 \pm 0.9$ and $11.1 \pm 0.9 \%$.

\section{Distribution of Carotenoids in Different Phases Present in Stomach During Digestion}

The distribution of all-trans $\beta$-carotene, lycopene, and lutein between the vegetable matrix, fat phase,

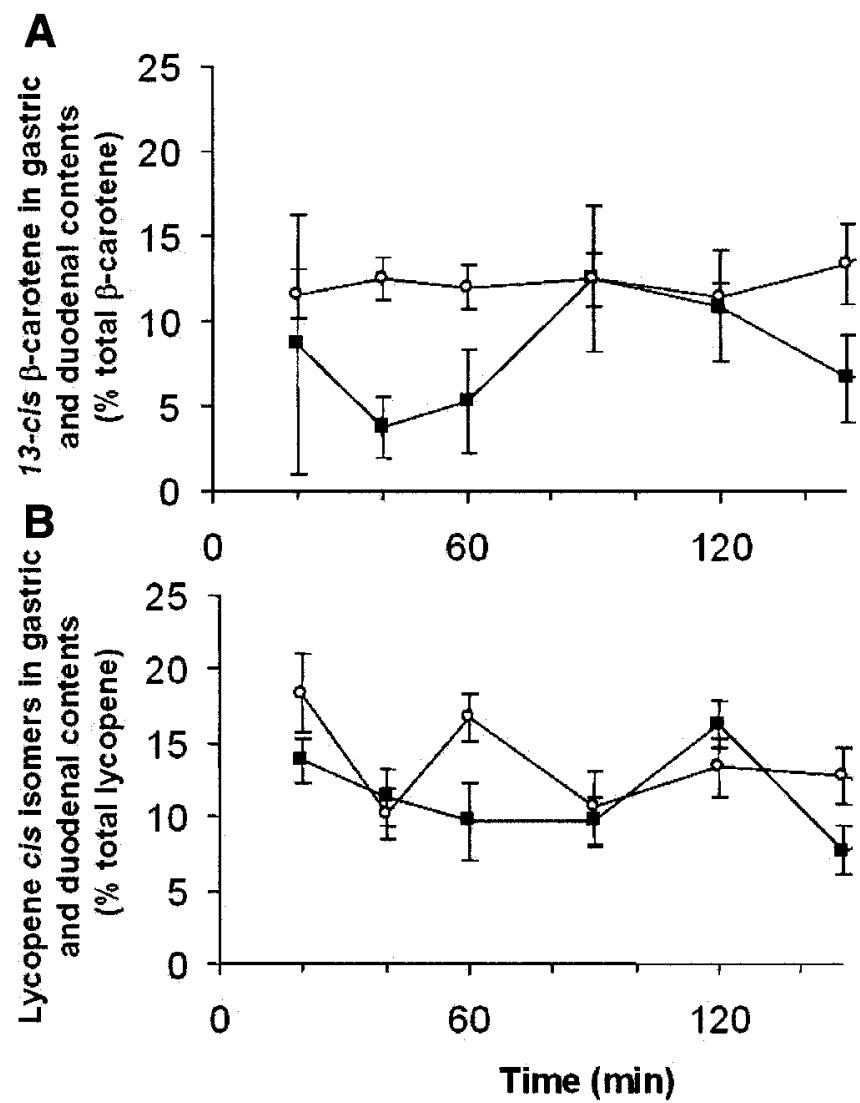

Fig. 3. Proportion of carotenoid cis isomers in the stomach (匹) and in the duodenum (O) during digestion. A: 13-cis $\beta$-carotene from the carrot meal. $B$ : lycopene cis isomers from the tomato meal. Values represent means \pm SE. ANOVA showed an effect of organ $(P<0.05)$ on the proportion of cis carotenoids in the GI contents. The post hoc Tukey-Kramer test showed that the 20- to 150-min mean proportion of carotenoid cis isomers was significantly higher in the duodenum than in the stomach. 
and aqueous phase present in the stomach during digestion is shown in Fig. 4. The first striking observation was that only trace amounts $(0-1.2 \%)$ of carotenoids were recovered in the aqueous phase of the stomach, whatever the digestion time. The second observation was that the proportion of all-trans $\beta$-carotene in the carrot matrix continuously decreased during digestion, whereas it increased in the fat phase. We noted that the results obtained for $\alpha$-carotene provided in the carrot meal were similar to those of all-trans $\beta$-carotene from the same meal (data not shown in the figure). Concerning all-trans lycopene, most (86-95\%) of it remained in the tomato matrix during digestion, and only $\sim 6 \%$ was recovered in the fat phase. Finally, all-trans lutein exhibited an intermediate figure, with $70-80 \%$ of this carotenoid remaining in the spinach matrix and $20-30 \%$ rapidly recovered in the fat phase.

\section{Proportion of Carotenoids in Aqueous (Micellar)} Phase Present in Duodenum

Only a very small proportion (between 1.8 and 6.9\%) of all-trans carotenoids was recovered in the aqueous phase of the duodenum (Fig. 5). There was an effect of carotenoid species on the proportion of carotenoid found in the aqueous phase. More precisely, the 20- to 150 -min mean proportions of lutein and all-trans $\beta$-carotene in the aqueous phase $(5.6 \pm 0.4$ and $4.8 \pm 0.3 \%$, respectively) were significantly higher than that of all-trans lycopene $(2.0 \pm 0.2 \%)$. The proportion of $\alpha$-carotene in the aqueous phase of the duodenum after the intake of the carrot meal was $4.7 \pm 0.6 \%$ (data not shown in the figure).

Figure 6 shows that the 20- to 150 -min mean proportions of 13-cis $\beta$-carotene recovered in the aqueous phase of the duodenum were significantly $(P<0.001)$ higher than that of all-trans $\beta$-carotene: $14.8 \pm 1.6 \mathrm{vs}$. $4.7 \pm 0.3 \%$. The results of lycopene cis isomers are not presented here owing to the very high variability of the data obtained.

\section{Postprandial Chylomicron Lipid and Carotenoid Responses to Test Meals}

The postprandial chylomicron triacylglycerol responses, as estimated by $0-8 \mathrm{~h}$ AUC, were not significantly different among the three test meals: $0.58 \pm$ $0.10,0.60 \pm 0.09$, and $0.54 \pm 0.10 \mathrm{mM} / \mathrm{h}$ for the tomato, carrot, and spinach meal, respectively (data not shown in the figures). For carotenoids, the first observation was that, although there was detectable all-trans lyco-

Fig. 4. Proportion (\%) of all-trans carotenoids recovered in the veg-

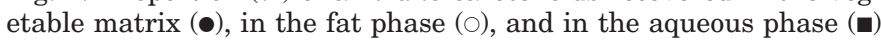
of stomach contents during digestion. A: all-trans $\beta$-carotene (measured after ingestion of the carrot meal). B: all-trans lycopene (after the tomato meal). $C$ : all-trans lutein (after the spinach meal). Carotenoids were measured in the whole samples, in the fat, and in the aqueous phase of the samples. The proportion of carotenoids in the vegetable matrix was calculated by subtracting the amount of carotenoids recovered in the fat and aqueous phases from the whole amount measured in the samples. Percentages were calculated from means of 10 measurements. pene in the chylomicron fraction, there was no significant variation in the postprandial all-trans lycopene response to the tomato test meal (as assessed by ANOVA with repeated measures, with time as a factor; Fig. 7). In contrast, there was an effect of time on the all-trans $\beta$-carotene concentrations in the chylomi-

\section{A}

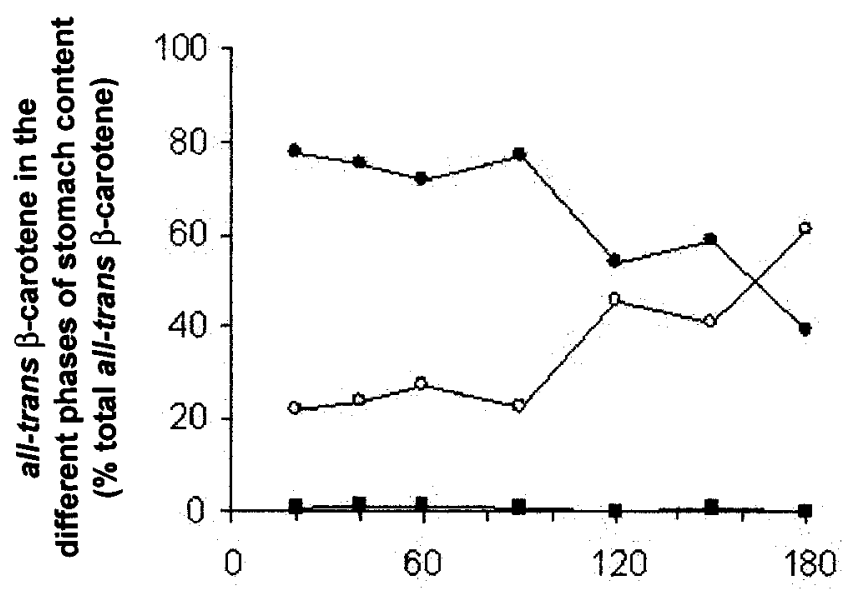

B

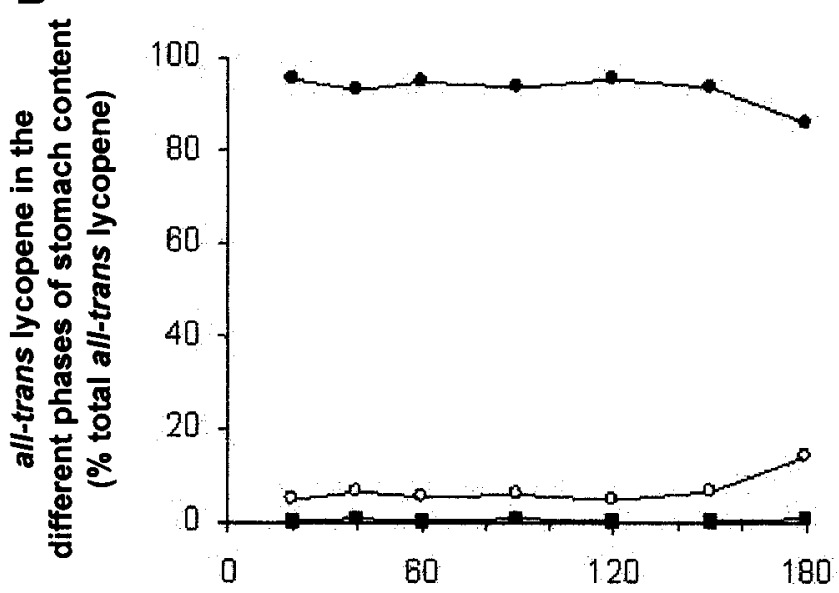

C

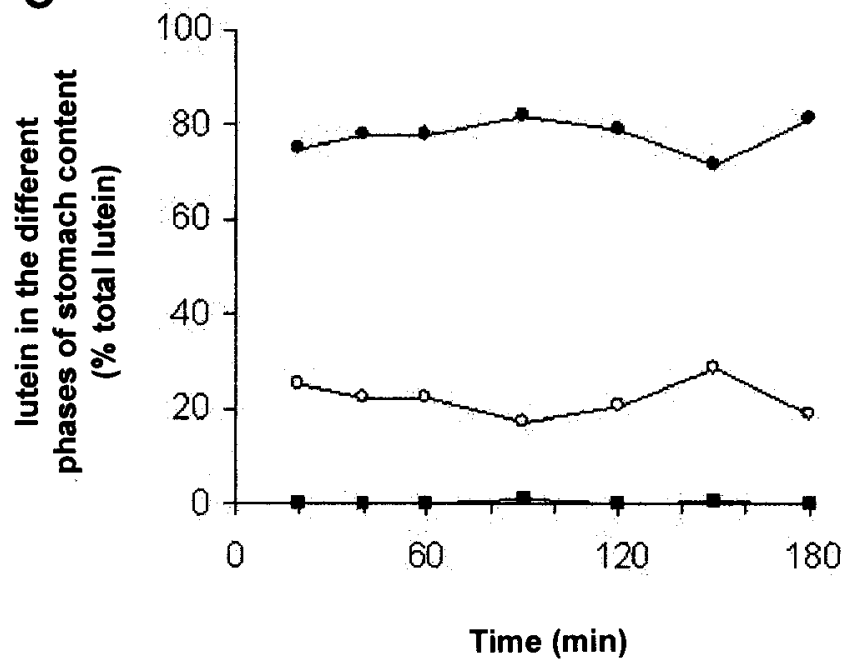




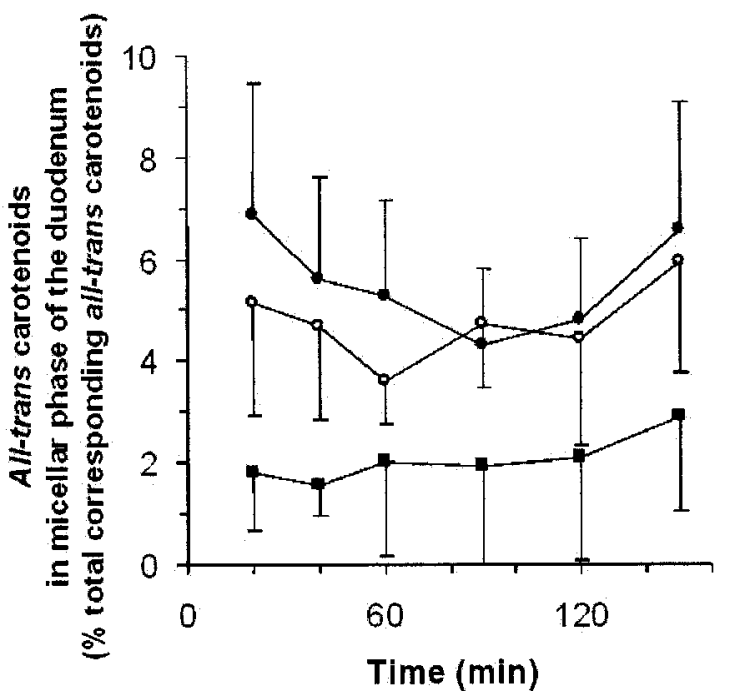

Fig. 5. Proportion (\%) of all-trans carotenoids in the aqueous (micellar) phase of duodenal content during digestion. $\bullet$, Lutein (after the spinach meal); $\bigcirc$ all-trans $\beta$-carotene (after the carrot meal); $\mathbf{n}$, all-trans lycopene (after the tomato meal). ANOVA showed an effect of carotenoid type $(P<0.0001)$ on the 20 - to 150 -min mean proportion of carotenoids in this phase of the duodenum. The post hoc Tukey-Kramer test showed that the 20- to 150 -min mean proportion of all-trans lycopene was significantly lower than that of the 2 other carotenoids.

crons after the carrot meal and on the lutein concentrations in the chylomicrons after the spinach meal (Fig. 7). In fact, there was no significant difference between the all-trans $\beta$-carotene response $(0-$ to 8 -h AUC) obtained after ingestion of the carrot meal $(24.2 \pm 4.3 \mathrm{nM} \cdot \mathrm{h})$ and the lutein response obtained after ingestion of the spinach meal $(24.0 \pm 4.3 \mathrm{nM} \cdot \mathrm{h})$. The second observation was that 13 -cis $\beta$-carotene was detected in most $(>63 \%)$ of the chylomicron samples measured after ingestion of the carrot meal, resulting in a significant variation in the concentration of the
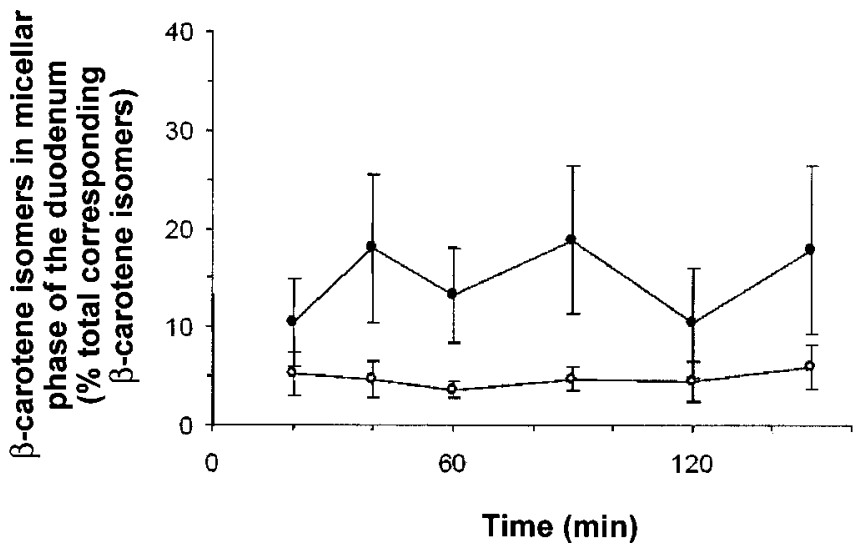

Fig. 6. Proportion (\%) of 13 -cis $(\bullet)$ and all-trans (०) $\beta$-carotene in the aqueous (micellar) phase of the duodenum. Values represent means $\pm \mathrm{SE}$ of 10 measurements. ANOVA showed no time effect but an effect of $\beta$-carotene isomer $(P<0.0001)$ on the 20 - to 150 -min mean proportion of $\beta$-carotene in this phase of the duodenum. The post hoc Tukey-Kramer test showed that the 20- to 150-min mean proportion of 13-cis $\beta$-carotene was significantly higher than that of the all-trans isomer.
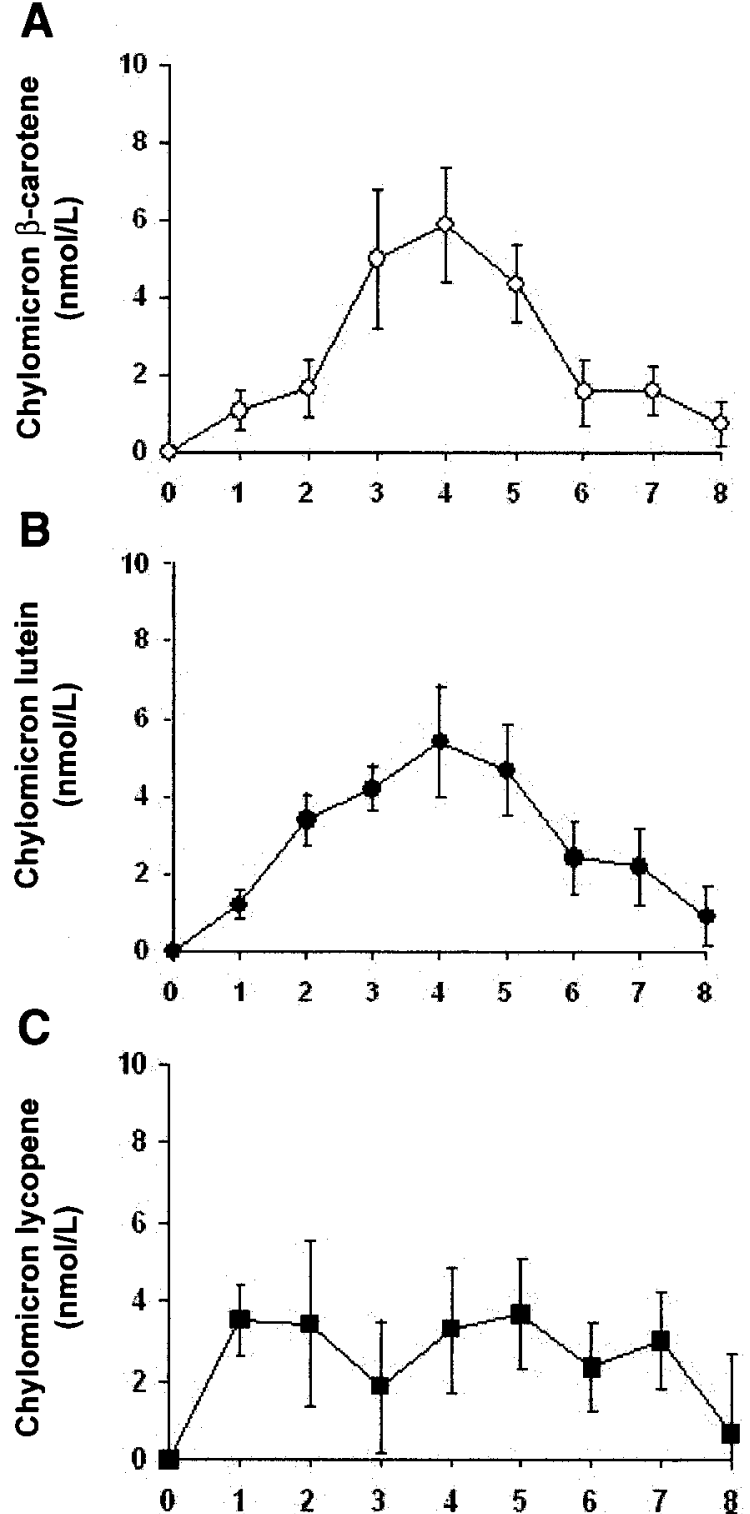

Fig. 7. Postprandial chylomicron carotenoid responses to the test meal. $\bigcirc$, All-trans $\beta$-carotene (after the carrot meal); $\bullet$, lutein (after the spinach meal); $n$, all-trans lycopene (after the tomato meal). Values (changes from fasting values) represent means \pm SE of 10 measurements. ANOVA showed a time effect on chylomicron $\beta$-carotene and lutein concentrations but no time effect on chylomicron lycopene concentrations.

13 -cis $\beta$-carotene in the postprandial period. Thus the calculated 13-cis $\beta$-carotene response was $2.8 \pm 0.9$ $\mathrm{nM} \cdot \mathrm{h}$. In contrast, although trace amounts of lycopene cis isomers were detected in some chylomicron samples ( $\sim 20 \%$ of the samples), most samples did not show detectable lycopene cis isomers, so there was no significant variation in the concentration of lycopene cis isomers in the chylomicrons after ingestion of the tomato meal.

\section{DISCUSSION}

The aim of this study was to obtain basic data on the fate of carotenoids in the human upper GI tract. Spe- 
cifically, we wanted to determine 1 ) whether there is a trans-to-cis isomerization of $\beta$-carotene and lycopene in the acidic environment of the stomach, 2) whether the stomach plays a role in the bioavailability of carotenoids, 3) how efficient the transfer of carotenoids from their vegetable matrix to micelles is, and 4) whether cis and trans isomers of carotenoids have different metabolisms in the gut lumen. To answer these questions, we followed the processing of carotenoids in the human upper GI tract by collecting chyme samples during the digestion of liquid test meals. This approach has already been used to study the metabolism of fat soluble vitamins in the human upper GI tract (5).

The first observation concerns the concentration of carotenoids in the stomach and duodenum during digestion. Curves exhibited by $\beta$-carotene and lycopene in the stomach were expected, with a gradual decrease in carotenoid concentration explained by the gastric emptying of the meals. The curve of lutein was significantly lower. It is difficult to explain such a difference, because the same amount of the main carotenoids was provided in each meal. The most likely hypothesis is that, although large samples of stomach content were collected to have a representative sample, the distribution of the vegetable matrix, i.e., chopped spinach leaves, was inhomogeneous in the stomach leading to an underestimation of lutein concentration. The relatively constant concentration of carotenoids in the duodenum can be explained by an equilibrium between the entry of carotenoids coming from the stomach and the exit of carotenoids either absorbed or transfered in the lower parts of the intestine.

Given that isomerization of trans carotenoids to $\mathrm{cis}$ carotenoids is promoted by contact with acids (36), our first goal was to assess whether there was any isomerization of carotenoids in the acidic environment of the stomach. The lack of any significant increase in the cis-trans $\beta$-carotene and cis-trans lycopene ratios in the stomach during digestion led to the conclusion that there was no significant cis-trans isomerization of these carotenoids in the human stomach. This result seems at variance with a recent result obtained in vitro (34), which showed an effect of acidic $\mathrm{pH}$ on lycopene isomerization. However, in that study, the isomerization was observed at the very low $\mathrm{pH}$ of 1.6 , a value found only in the fasting stomach and not during the digestion of the complex lycopene-rich meal used in this study (see Fig. 1).

The fact that the cis-trans $\beta$-carotene and lycopene ratios were significantly higher in the duodenum than in the stomach was noteworthy. A first hypothesis is that there was a lower bioaccessibility (defined as the ease with which the carotenoids are solubilized within the mixed micelles from the vegetable matrix) of the cis isomers compared with the trans isomers, resulting in a lower absorption efficiency for the cis isomers. However, this is unlikely because there was a higher proportion of 13-cis $\beta$-carotene than of all-trans $\beta$-carotene in the aqueous phase of the duodenum (Fig. 6), suggesting a better bioaccessibility of the cis isomers, and it has been shown that, when artificially incorporated in micelles, both isomers are absorbed with the same efficiency. A second hypothesis is that cis isomers were secreted in the bile, resulting in an increased cis-trans ratio in the duodenum. However, although we detected all-trans $\beta$-carotene and lutein in the fasting duodenal samples, in agreement with previous results (24), we did not detect significant amounts of carotenoid cis isomers in the fasting samples of the duodenum. A third hypothesis is that there was a cis-to-trans isomerization of carotenoids in the duodenum, but we have no evidence of this.

Because the carotenoids were initially present only in the vegetable matrices, their presence in the fat phase of the stomach content must have resulted from their transfer from the vegetable matrices to this phase. Although such a transfer has been described in vitro (35), this is the first time that it has been measured in humans. The data collected show that the different carotenoids were transferred with different efficiencies. This may be explained in several ways. The in vitro results (35) suggest that there was an effect of $\mathrm{pH}$ on the transfer efficiency. However, this hypothesis can be rejected, because there was no significant meal effect on stomach $\mathrm{pH}$. A second hypothesis is that there was a matrix effect, i.e., that the different vegetable matrices (carrot, spinach, and tomato) have different abilities to release carotenoids (due to different fiber composition or different intracellular locations of carotenoids). This second hypothesis can also be rejected because the kinetics of transfer of $\beta$-carotene from spinach (data not shown in the figures) mimicked that of $\beta$-carotene from carrots and was very different from that of lutein from spinach. A third hypothesis is that there was an effect of triacylglycerol lipolysis on the transfer. However, although there was a significant matrix effect on gastric triacylglycerol lipolysis, there was no relationship between the proportion of lipids remaining as triacylglycerols, which reflects triacylglycerol lipolysis efficiency, and transfer efficiency. A fourth hypothesis is that the transfer of carotenoids depends on their relative solubility in the fat phase. This hypothesis seems plausible because there was a strongly positive relationship $(r=0.99$, $P=0.01$ ) between carotenoid solubility in tri-C18 triacylglycerols (3) and the proportion of carotenoids in the fat phase at $180 \mathrm{~min}$ digestion. The last hypothesis is that the size of the lipid droplets, and thus the area for exchange, affected the transfer efficiency. The positive relationship ( $r=0.98, P=0.08$ ) between the mean diameter of emulsions recovered in the stomach and the transfer efficiency at 180 min suggested that some parameter related to the quality of the interface might also be involved in the transfer. Whatever the mechanism involved, these data suggest that the stomach plays an important role in the bioaccessibility of carotenoids by initiating their release from their vegetable matrices.

Because it is assumed that carotenoids are absorbed only when they are solubilized in micelles, the very low percentage of carotenoids recovered in the aqueous (micellar) phase of the duodenum suggests that only a 
very low proportion of carotenoids, supplied in their natural vegetable matrix, is available for absorption. This result is in remarkable agreement with a recent study performed in CaCo-2 (10). Indeed it was shown that the extent of absorption of carotenoids was comprised of between $11 \%$ for all-trans $\beta$-carotene and $2.5 \%$ for all-trans lycopene. It is also in agreement with a study that estimated absorption efficiency from chylomicron response (32). With this method, it was estimated that $1.4 \mathrm{mg}$ of $40 \mathrm{mg} \beta$-carotene $(3.5 \%)$ and $1 \mathrm{mg}$ of $40 \mathrm{mg}$ lycopene $(2.5 \%)$ were absorbed in humans, values close to the solubility values measured here, i.e., 4.8 and $2.0 \%$. However, note that these solubility values would have been probably different if purified carotenoids were used. Indeed, it is well known that carotenoids compete for absorption $(42,44)$ and the vegetables ingested contained several carotenoids (see MATERIALS AND METHODS). However, the aim of this study was to provide basic data on the digestion of vegetableborne carotenoids, which are mostly recovered with other carotenoids species in vegetables.

The fact that the percentage of all-trans lycopene recovered in the micellar phase of the duodenum was significantly lower than that of all-trans $\beta$-carotene and lutein was noteworthy. It is in remarkable agreement with a recent result that showed that the extent of absorption of $\beta$-carotene, $\alpha$-carotene, and lutein by CaCo-2 cells was higher than that of lycopene (10). It suggests that the availability for absorption of lycopene is less efficient than that of the other carotenoids. The question arises whether this difference depends on a vegetable matrix effect or on some other effect. Although it was not possible to accurately measure the proportion of $\beta$-carotene in micelles after the tomato meal (due to the very low amount of $\beta$-carotene provided by this meal, i.e., $\sim 1 \mathrm{mg}$ ), the fact that the proportion of $\beta$-carotene from spinach was similar to that of $\beta$-carotene from carrot (data not shown in the figures) suggests that the efficiency of transfer to micelles does not depend on vegetable matrix characteristics. Because carotenoids are assumed to be entrapped in the fat phase of dietary emulsions and because it has been suggested that triacylglycerol lipolysis enhances the release of the carotenes $(3,43)$, we suggested that the efficiency of triacylglycerol lipolysis affects the carotenoid transfer to micelles. This hypothesis seemed valid, because there was a strong negative relationship ( $r=-0.998, P=0.036)$ between the concentration of triacylglycerols in the duodenum, which reflects lipolysis, and the percentage of carotenoids found in the micellar phase at $1 \mathrm{~h}$ of digestion. The lowest solubility of lycopene in the micellar phase may result from the lower $\mathrm{pH}$ observed in the duodenum during the digestion of the tomato meal (Fig. 1). It has recently been shown that the efficiency of carotenoid transfer from emulsion lipid droplets to micelles diminishes as the $\mathrm{pH}$ decreases (43). It may also result from its higher hydrophobicity. It is remarkable that the least hydrophobic carotenoid (7), lutein, had the highest solubility in micelles, whereas the most hydrophobic carotenoid, lycopene, had the lowest solubility.
This hypothesis is in agreement with previous results $(14,45)$ that found a higher relative bioavailability of lutein compared with $\beta$-carotene.

The higher proportion of 13-cis $\beta$-carotene in the micellar phase may be due to either a higher micelle transfer efficiency, a lower absorption efficiency of micellar 13-cis $\beta$-carotene, or both. This hypothesis is supported by the fact that the absorption efficiency of 13 -cis $\beta$-carotene is significantly lower than that of the all-trans isomer (10) and by the fact (27) that the cis isomer is more efficiently transferred to micelles than the all-trans isomer. The reason for this is unknown but could be due to either a different partitioning of the two isomers between the core and the surface of emulsion lipid droplets (3) or different solubilities of the two isomers in micelles. Finally, the fact that the 13-cis-toall-trans $\beta$-carotene ratio measured in the micellar phase (13.3) was very close to the 13-cis-to-all-trans $\beta$-carotene ratio measured in the chylomicrons (11.5) suggests that 13 -cis $\beta$-carotene does not undergo the cis-to-trans isomerization previously demonstrated for 9 -cis $\beta$-carotene (48) in the enterocyte.

Before discussion on the postprandial chylomicron carotenoid responses, it should be stated that these responses could not be compared in intensity with those obtained in other studies with similar doses of lipids and carotenoids, because an important proportion of lipids and carotenoids was taken in the gut during digestion for the different analysis. The fact that chylomicron all-trans lycopene did not significantly vary in the postprandial period, whereas alltrans $\beta$-carotene and lutein did, is in remarkable agreement with the data obtained in the duodenum, with a lower solubility of lycopene in micelles compared with the two other carotenoids. The fact that cis isomers of lycopene were hardly detected in chylomicrons can be explained by a low absorption efficiency, an isomerization to the trans isomer in the enterocyte, or a specific transport via the portal pathway. The first hypothesis can reasonably be rejected, because it has been suggested that cis isomers of lycopene artificially incorporated in micelles are more bioavailable than all-trans isomers of lycopene (2). The fact that cis isomers of lycopene are detected in human plasma and tissues $(18,38,40)$, accounting for $>50 \%$ total plasma lycopene (38), plus the fact that our data suggest that they are poorly transported by the chylomicrons and thus poorly absorbed strongly suggests that a trans-tocis isomerization of this carotenoid, possibly due to antioxidant reactions of lycopene (30), occurs in the body at a postenterocyte level.

In conclusion, this study provides some new data on the fate of carotenoids in the human upper GI tract. The main findings are that 1 ) there is no significant cis-trans isomerization of $\beta$-carotene and lycopene in the human stomach, 2) the stomach plays a significant role in the bioavailability of carotenoids by initiating their transfer from the vegetable matrix to the fat phase of the meal, 3) the proportion of carotenoids recovered in the micellar phase of the duodenum is very low $(<7 \%)$, which probably explains the poor bio- 
availability of these phytomicroconstituents, 4) 13-cis $\beta$-carotene is more fully solubilized in micelles than the all-trans isomer, explaining its higher bioavailability, and 5) cis isomers of lycopene are sparingly secreted in the chylomicrons, suggesting a postenterocyte origin for these isomers in the body.

We thank Prof. S. Southon (Institute of Food Research, Norwich, UK) for the excellent coordination of this European project, Dr. R. Faulk (Institute of Food Research) for advice on carotenoid extraction from vegetables, C. G. Rodenas (Nutrition Department, Nestlé Research Center, Lausanne, Switzerland) for a gift of whey proteins, Dr. H. van Amelsvoort (Unilever Health Institute, Unilever Research, Vlaardingen, Netherlands) for a gift of stripped sunflowerseed oil, L. Morin and P. Rousset for help in blood collection, and Marion Brandolini for the analysis of the diet diaries.

This research was supported by the European Union FAIR project CT97-3100.

\section{REFERENCES}

1. Armand M, Borel P, Pasquier B, Dubois C, Senft M, Andre M, Peyrot J, Salducci J, and Lairon D. Physicochemical characteristics of emulsions during fat digestion in human stomach and duodenum. Am J Physiol Gastrointest Liver Physiol 271: G172-G183, 1996.

2. Boileau AC, Merchen NR, Wasson K, Atkinson CA, and Erdman JW Jr. cis-Lycopene is more bioavailable than translycopene in vitro and in vivo in lymph-cannulated ferrets. $J$ Nutr 129: $1176-1181,1999$.

3. Borel P, Grolier P, Armand M, Partier A, Lafont H, Lairon D, and Azais-Braesco V. Carotenoids in biological emulsions: solubility, surface-to-core distribution, and release from lipid droplets. J Lipid Res 37: 250-261, 1996.

4. Borel P, Grolier P, Mekki N, Boirie Y, Rochette Y, Le Roy B, Alexandre-Gouabau MC, Lairon D, and Azais-Braesco V. Low and high responders to pharmacological doses of betacarotene: proportion in the population, mechanisms involved and consequences on beta-carotene metabolism. J Lipid Res 39: 2250-2260, 1998.

5. Borel P, Pasquier B, Armand M, Tyssandier V, Grolier P, Alexandre-Gouabau MC, Andre M, Senft M, Peyrot J, Jaussan V, Lairon D, and Azais-Braesco V. Processing of vitamin $\mathrm{A}$ and $\mathrm{E}$ in the human gastrointestinal tract. $A m J$ Physiol Gastrointest Liver Physiol 280: G95-G103, 2001.

6. Chug-Ahuja JK, Holden JM, Forman MR, Mangels AR, Beecher GR, and Lanza E. The development and application of a carotenoid database for fruits, vegetables, and selected multicomponent foods. J Am Diet Assoc 93: 318-323, 1993.

7. Cooper DA, Webb DR, and Peters JC. Evaluation of the potential for olestra to affect the availability of dietary phytochemicals. J Nutr 127, Suppl 8: S1699-S1709, 1997.

8. De Pee S, West CE, Permaesih D, Martuti S, Muhilal, and Hautvast JG. Orange fruit is more effective than are darkgreen, leafy vegetables in increasing serum concentrations of retinol and beta-carotene in schoolchildren in Indonesia. Am $J$ Clin Nutr 68: 1058-1067, 1998.

9. Dubois C, Armand M, Azais-Braesco V, Portugal H, Pauli AM, Bernard PM, Latge $C$, Lafont $H$, Borel $P$, and Lairon D. Effects of moderate amounts of emulsified dietary fat on postprandial lipemia and lipoproteins in normolipidemic adults. Am J Clin Nutr 60: 374-382, 1994.

10. During A, Hussain MM, Morel DW, and Harrison EH. Carotenoid uptake and secretion by $\mathrm{CaCo}-2$ cells: beta-carotene isomer selectivity and carotenoid interactions. J Lipid Res 43: 1086-1095, 2002.

11. Erdman JW, Poor CL, and Dietz JM. Factors affecting the bioavailability of vitamin A, carotenoids, and vitamin E. Food Technol 42: 214-221, 1988.

12. Faulks RM, Hart DJ, Wilson PD, Scott KJ, and Southon S. Absorption of all-trans and 9-cis beta-carotene in human ileostomy volunteers. Clin Sci (Colch) 93: 585-591, 1997.
13. Folch J, Lees M, and Sloane Stanley GH. A simple method for the isolation and purification of total lipids from animal tissues. J Biol Chem 226: 497-509, 1957.

14. Gartner C, Stahl W, and Sies H. Preferential increase in chylomicron levels of the xanthophylls lutein and zeaxanthin compared to $\beta$-carotene in the human. Int J Vitam Nutr Res 66: 119-125, 1996.

15. Gaziano JM, Johnson EJ, Russell RM, Manson JE, Stampfer MJ, Ridker PM, Frei B, Hennekens CH, and Krinsky NI. Discrimination in absorption or transport of betacarotene isomers after oral supplementation with either alltrans- or 9-cis-beta-carotene. Am J Clin Nutr 61: 1248-1252, 1995.

16. Hieber AD, King TJ, Morioka S, Fukushima LH, Franke AA, and Bertram JS. Comparative effects of all-trans betacarotene vs. 9-cis beta-carotene on carcinogen-induced neoplastic transformation and connexin 43 expression in murine 10T1/2 cells and on the differentiation of human keratinocytes. Nutr Cancer 37: 234-244, 2000.

17. Hollander D and Ruble PE. $\beta$-carotene intestinal absorption: bile, fatty acid, $\mathrm{pH}$, and flow rate effects on transport. Am J Physiol Endocrinol Metab Gastrointest Physiol 235: E686-E691, 1978.

18. Holloway DE, Yang M, Paganga G, Rice-Evans CA, and Bramley PM. Isomerization of dietary lycopene during assimilation and transport in plasma. Free Radic Res 32: 93-102, 2000.

19. Horowitz M, Jones K, Edelbroek MA, Smout AJ, and Read NW. The effect of posture on gastric emptying and intragastric distribution of oil and aqueous meal components and appetite. Gastroenterology 105: 382-390, 1993.

20. Krinsky NI. Actions of carotenoids in biological systems. Annu Rev Nutr 13: 561-587, 1993.

21. Krinsky NI. Mechanism of action of biological antioxidants. Proc Soc Exp Biol Med 200: 248-254, 1992.

22. Lampe JW. Health effects of vegetables and fruit: assessing mechanisms of action in human experimental studies. Am J Clin Nutr 70 Suppl 3, 475S-490S, 1999.

23. Lavy A, Amotz AB, and Aviram M. Preferential inhibition of LDL oxidation by the all-trans isomer of beta-carotene in comparison with 9-cis beta-carotene. Eur J Clin Chem Clin Biochem 31: 83-90, 1993.

24. Leo MA, Ahmed S, Aleynik SI, Siegel JH, Kasmin F, and Lieber CS. Carotenoids and tocopherols in various hepatobiliary conditions. J Hepatol 23: 550-556, 1995.

25. Lessin WJ, Catigani GL, and Schwartz SJ. Quantification of cis-trans isomers of provitamin A carotenoids in fresh and processed fruits and vegetables. Agr Food Chem 45: 3728-3732, 1997.

26. Levin G and Mokady S. Antioxidant activity of 9-cis compared to all-trans beta-carotene in vitro. Free Radic Biol Med 17: 77-82, 1994.

27. Levin G and Mokady S. Incorporation of all-trans- or 9-cisbeta-carotene into mixed micelles in vitro. Lipids 30: 177-179, 1995.

28. Levin G, Yeshurun M, and Mokady S. In vivo antiperoxidative effect of 9-cis beta-carotene compared with that of the all-trans isomer. Nutr Cancer 27: 293-297, 1997.

29. Lyan B, Azais-Braesco V, Cardinault N, Tyssandier V, Borel P, Alexandre-Gouabau MC, and Grolier P. Simple method for clinical determination of 13 carotenoids in human plasma using an isocratic high-performance liquid chromatographic method. J Chromatogr B Biomed Appl 751: 297-303, 2001.

30. Muller H, Bub A, Watzl B, and Rechkemmer G. Plasma concentrations of carotenoids in healthy volunteers after intervention with carotenoid-rich foods. Eur J Nutr 38: 35-44, 1999.

31. Novotny JA, Dueker SR, Zech LA, and Clifford AJ. Compartmental analysis of the dynamics of beta-carotene metabolism in an adult volunteer. J Lipid Res 36: 1825-1838, 1995.

32. O'Neill ME and Thurnham DI. Intestinal absorption of $\beta$-carotene, lycopene and lutein in men and women following a stan- 
dard meal: response curves in the triacylglycerol-rich lipoprotein fraction. Br J Nutr 79: 149-159, 1998.

33. Parker RS, Swanson JE, You CS, Edwards AJ, and Huang T. Bioavailability of carotenoids in human subjects. Proc Nutr Soc 58: 155-162, 1999.

34. Re R, Fraser PD, Long M, Bramley PM, and Rice-Evans C. Isomerization of lycopene in the gastric milieu. Biochem Biophys Res Commun 281: 576-581, 2001.

35. Rich GT, Fillery-Travis A, and Parker ML. Low pH enhances the transfer of carotene from carrot juice to olive oil. Lipids 33: 985-992, 1998.

36. Rodriguez-Amaya DB. Changes in carotenoids during processing and storage of foods. Arch Latinoam Nutr 49, Suppl 3: 38S-47S, 1999 .

37. Shi J and Le Maguer M. Lycopene in tomatoes: chemical and physical properties affected by food processing. Crit Rev Biotechnol 20: 293-334, 2000.

38. Stahl W, Schwarz W, Sundquist AR, and Sies H. cis-trans Isomers of lycopene and beta-carotene in human serum and tissues. Arch Biochem Biophys 294: 173-177, 1992.

39. Stahl W, Schwarz W, Vonlaar J, and Sies H. All-trans betacarotene preferentially accumulates in human chylomicrons and very low density lipoproteins compared with the 9-cis geometrical isomer. J Nutr 125: 2128-2133, 1995.

40. Stahl W and Sies H. Uptake of lycopene and its geometrical isomers is greater from heat-processed than from unprocessed tomato juice in humans. J Nutr 121: 2161-2166, 1992.

41. Steghens JP, Lyan B, Le Moel G, Galabert C, Fayol V, Faure H, Grolier P, Cheribi N, Dubois F, and Nabet F. Measurement of carotenoids by high pressure liquid chromatog- raphy: from difficulties to solutions. Ann Biol Clin (Paris) 58: 327-335, 2000.

42. Tyssandier V, Cardinault N, Caris-Veyrat C, Amiot MJ, Grolier P, Bouteloup C, Azais-Braesco V, and Borel P. Vegetable-borne lutein, lycopene, and beta-carotene compete for incorporation into chylomicrons, with no adverse effect on the medium-term (3-wk) plasma status of carotenoids in humans. Am J Clin Nutr 75: 526-534, 2002.

43. Tyssandier V, Lyan B, and Borel P. Main factors governing the transfer of carotenoids from emulsion lipid droplets to micelles. Biochim Biophys Acta 1533: 285-292, 2001.

44. Van den Berg H. Carotenoid interactions. Nutr Rev 57: 1-10, 1999.

45. Van Het Hof KH, Brouwer IA, West CE, Haddeman E, Steegers-Theunissen RP, van Dusseldorp M, Weststrate JA, Eskes TK, and Hautvast JG. Bioavailability of lutein from vegetables is 5 times higher than that of beta-carotene. Am J Clin Nutr 70: 261-268, 1999.

46. Van Het Hof KH, West CE, Weststrate JA, and Hautvast JG. Dietary factors that affect the bioavailability of carotenoids. J Nutr 130: 503-536, 2000.

47. Van Vliet T, Schreurs WH, and van den Berg H. Intestinal beta-carotene absorption and cleavage in men: response of betacarotene and retinyl esters in the triglyceride-rich lipoprotein fraction after a single oral dose of beta-carotene. Am J Clin Nutr 62: 110-116, 1995.

48. You CS, Parker RS, Goodman KJ, Swanson JE, and Corso TN. Evidence of cis-trans isomerization of 9-cis-beta-carotene during absorption in humans. Am J Clin Nutr 64: 177-183, 1996.

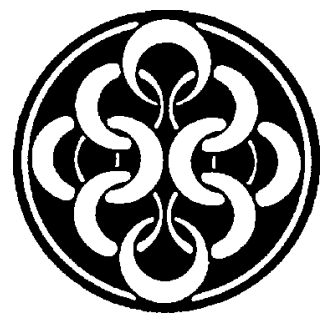

